\title{
Caracterización diferencial de la investigación social
}

\author{
Dr. Raúl Villarroel Soto \\ (Universidad de Chile, rvillarr@uchile.cl)
}

\begin{abstract}
Resumen
¿Cómo podríamos caracterizar un criterio distintivo que permita identificar la naturaleza de la investigación social? Mi apuesta apunta a considerar a la ciencia social como un ámbito en donde la empatía y la interpretación son elementos determinantes para los procesos de investigación. Bajo esta consideración, el trabajo del investigador social se analiza desde un compromiso ético desde el que puede ser definido como una actividad social. Considero que la investigación social no solamente puede ser considerada como un procedimiento técnico, sino que debe admitir una reflexión e identificación de los valores involucrados en su formulación en función de resguardar los derechos de su campo de estudio. De esta manera, el punto de vista de los investigadores acerca de la humanidad y la sociedad constituyen un factor decisivo para promover los componentes éticos del conjunto de prácticas representadas por la investigación social.
\end{abstract}

Palabras clave: investigación social, ética, responsabilidad, derechos.

\begin{abstract}
How could we characterize a distinctive criterion that allows to identify the nature of social research? My proposal aims to consider social science as a field where empathy and interpretation play a key role in the research processes. Under this scope, the work of the social researcher is analyzed from an ethical commitment, leading to understand it as a social activity. I consider that social research cannot be solely understood as a technical procedure, since it must also admit the reflection and identification of the values that are involved in its formulation in accordance with the safeguard of the rights specific to its field of study. By doing so, the point of view of researchers regarding humanity and society make up a decisive factor in promoting the ethical components contained in the set of practices represented by social research.
\end{abstract}

Keywords: social research, ethics, responsibility, rights. 


\section{Introducción}

La relación entre ciencia y ética no ha tenido una historia de convergencia fácil, el siglo XX fue testigo de una problemática mal resuelta donde la incomprensión no pocas veces dio paso al desdén. El primero que cuestionó la posibilidad de una conexión entre el quehacer de la ciencia y el ámbito ético fue el filósofo austriaco Ludwig Wittgenstein, quien en la cuarta tesis de su Tractatus Logico-Philosophicus (1997) distinguió entre "proposiciones con sentido" -aquellas que describen el mundo y pueden verificarse empíricamente- y las "proposiciones sin sentido" -que intentan referirse a realidades que traspasan los límites del mundo y del lenguaje- entre las que se incluyen las afirmaciones de la ética. El Círculo de Viena profundizó esta postura al afirmar que lo propio de la racionalidad científica es trabajar exclusivamente con hechos, enunciándolos y verificándolos, una racionalidad descriptiva y resolutiva pero nunca valorativa. Precisamente esta diferencia entre hechos y valores llegó a ser el fundamento último de la pretendida neutralidad de la ciencia que tanto se defendió en la primera mitad del siglo XX.

Así las cosas, hubo que esperar a que el impacto de la Segunda Guerra Mundial golpeara la conciencia de la humanidad para que se retomara el vínculo entre ciencia y ética. La sospecha de estar en un mundo amenazado -cuando no francamente herido- convirtió el escenario intelectual en un campo de lucha permanente entre complacientes y críticos radicales de la responsabilidad ética que ha tenido o de la que ha carecido la ciencia. En este contexto epistemológico, Kuhn (1962), con su texto La estructura de las revoluciones científicas, dio pie para que las ciencias -sobre todo las ciencias naturales- se abrieran al contexto ético-valorativo en que se desarrollan las teorías. De la misma forma, Merton - desde las ciencias sociales- refutó la distinción entre hechos - propios de la ciencia- y valores -territorio exclusivo de la ética-, defendiendo al interior de los postulados "un conjunto de valores y normas culturales que gobiernan las actividades llamadas científicas" (Merton, 1977, p. 356).

Se abre así una nueva etapa donde el debate ético se toma el horizonte de la investigación científica, momento en que se busca establecer acuerdos normativos para asegurar una convivencia armónica entre ambos ámbitos. Como manifestación de ello surgen la Declaración de Helsinki y el Informe Belmont, los cuales son expresión de un cambio de conciencia en la 
comunidad científica que parece allanarse a un nuevo horizonte de responsabilidad en su quehacer.

Lo que evidentemente emerge hoy en día es la pregunta respecto de si es o no la ciencia la que determina los nuevos roles y modelos sociales que caracterizan a la sociedad de nuestro tiempo y cuáles son las estrategias que la sociedad tendría para dar cuenta adecuadamente de ellos. El mejor análisis de los juicios, criterios o instituciones científicas vigentes, es que estas sean sometidas a escrutinio público, y que puedan demostrar que son capaces de superar las objeciones o críticas que se pudieran plantear en su contra. Parece sensato pensar que la comunidad investigue y debata respecto de aquellos juicios, criterios e instituciones, y que, en consecuencia, lo que todos ellos resulten finalmente ser se corresponda, al menos en parte, con el resultado de tal escrutinio y discusión (MacIntyre, 2001, pp. 185-186).

Como sea, quienes se comprometan en la tarea de una evaluación particularmente ética de la ciencia, no deberían limitarse a una mera acción técnica, ni mucho menos solo administrativa, sino tener la capacidad de dimensionar la problemática ética en su justa medida y contar con la sensibilidad para percibir, sobre todo, el lugar del sufrimiento humano derivado de la intervención investigativa sobre las poblaciones humanas, definiendo las estrategias para ordenar el curso de la ciencia conforme a su ineludible responsabilidad social e impedir los efectos deletéreos que de su praxis pudieran eventualmente derivarse.

Ahora bien, teniendo como referencia general lo que se acaba de señalar y buscando profundizar en la sospecha respecto de un eventual desajustamiento que se produciría a la hora de pensar en una aplicación estricta de las exigencias impuestas por la Ley 20.120 a la investigación social, parece imprescindible visualizar un criterio distintivo que permita identificar su naturaleza específica. Dejamos en claro, por supuesto, que este intento de esclarecimiento tendrá como único encuadre y expectativa la posibilidad de comprenderla en estricta vinculación con la ética investigativa y de ningún modo aventurar definiciones epistemológicas exhaustivas o concluyentes respecto del carácter esencial de la ciencia social. Entendemos que esa es una tarea privativa de los especialistas en la materia. 


\section{La investigación social}

La investigación social, en particular, puede definirse como un estilo de pensamiento (Rose, 2012; Fleck, 1997). Ello porque constituye un modo particular de pensar, ver y ejercer la praxis del saber. Supone formular enunciados que solo son posibles e inteligibles en el marco de ese modo de pensar. Los elementos (términos, conceptos, afirmaciones, referencias, relaciones) se organizan en configuraciones con cierto carácter, que actúan como argumentos y explicaciones. Los fenómenos se ordenan y clasifican conforme a singulares regímenes de significación. Ciertas cosas se aprecian y entienden datos, los que se recopilan y emplean de particular manera, al mismo tiempo que se conciben y estructuran sistemas para que operen en la categoría de modelos. Todo este conjunto de prácticas científicas está organizado en función de su visibilización a través de experimentos y pruebas. Un "estilo de pensamiento" supone ser miembro de una "comunidad de pensamiento" (Fleck, 1997) en el marco de una disciplina o subdisciplina, así como un conocimiento íntimo de las relaciones de poder y estatus de ese colectivo. Un estilo de pensamiento en un área científica entraña un modo de identificar dificultades, cuestionar argumentaciones, identificar fallas explicativas: un modo de crítica, de detección de errores, de corrección de errores.

En particular y de manera distintiva, los estudios culturales y sociales tienen que ver con cuestiones humanas; considerando la promoción del desarrollo integral y el mejoramiento de las personas y la sociedad presente y futura, tienen que ver con acciones y relaciones, con instituciones, creencias y desarrollos históricos, trabajos y tradiciones, lenguaje, formas de pensamiento y comunicación. En la ciencia social la empatía y la interpretación son prerrequisitos para los procesos de investigación. De este modo, el conocimiento resulta siempre ser una construcción y una interpretación. En la ciencia social el proceso de producción del conocimiento es en último término interactivo y la singularidad tiene legitimidad científica, a diferencia de otros ámbitos del saber donde puede constituir una limitación insalvable.

Ello es la expresión concreta de la necesidad de reconocimiento del factor de subjetividad que es inherente a toda intervención social. Tal dimensión subjetiva está directamente vinculada a las posibilidades hermenéuticas del observador y condiciona el estado de desarrollo del conocimiento disciplinar, el que a su vez está definido por la naturaleza esencialmente simbólica 
y polimórfica de la realidad que busca conocer, lo que hace que el conocimiento logrado siempre sea asintótico. Sin embargo, esto requiere que los investigadores nunca dejen de considerar que sus propias actitudes pueden llegar a teñir sus investigaciones, sus fuentes de información y el justo balance entre las interpretaciones posibles a que su trabajo les pueda conducir. En este sentido, la investigación social se distingue por la ineludible incidencia del punto de vista de los investigadores acerca de la humanidad y la sociedad, constituyendo un factor que a menudo más que limitarla o deslegitimarla en verdad la enriquece.

\section{E1 objeto de atención del investigador social}

De esta manera, la población de estudio se presenta como una de las cuestiones fundamentales y diferenciales que nos permiten comprender al investigador social, en función de dotar su trabajo del compromiso ético que define a la ciencia como una actividad social. Estas cuestiones tienen que ver con la importancia que asigne al afinamiento de la caracterización de la población estudiada, por ejemplo, atendiendo a su condición de vulnerabilidad, sobre todo si se trata de niños o inmigrantes, o personas reclusas, etcétera. Importante resulta ser en este mismo sentido el reconocimiento que haga del hecho de que la población en estudio es usualmente diversa y no necesariamente adolece de condiciones patológicas o carenciadas.

No obstante, ninguna de estas circunstancias lo eximen del deber de prevenir riesgos de desestabilización emocional eventual o permanente de tales participantes en una investigación como consecuencia de la intervención llevada a cabo. Por ello, la investigación social enfrenta la necesidad de definir anticipadamente e implementar de manera efectiva los correspondientes protocolos de asistencia y contención permanente de los participantes. Es necesario advertir que, al momento de recurrir a los protocolos, estos no deben generan ningún costo.

Ciertamente, la marca de distinción de la investigación social y que da lugar al factor que la diferencia de otros órdenes investigativos, como por ejemplo el de la investigación biomédica, plantea algunos desafíos que en ocasiones podrían llegar a tensionar las exigencias que canónicamente, y conforme ha sido establecido por la legislación (en Chile la Ley 20.120), toda investigación está conminada a cumplir. Un caso ilustrativo de ello lo constituye el requisito de 
resguardo del anonimato que se ha establecido como medida de protección para la intimidad de los sujetos que proveen la información levantada por los protocolos investigativos. En el caso de la investigación social, dada la naturaleza de algunos diseños metodológicos, surge la necesidad de reconocer la provisionalidad de tal requisito de anonimato, debido a que ciertas investigaciones se validan precisamente por la necesaria identificación de los participantes. Más o menos del mismo tipo de excepcionalidades se trata cuando se debe considerar la posibilidad de aceptar la eventual necesidad de ocultamiento justificado de determinada información respecto de la intervención para no interferir en las respuestas buscadas ni inducir comportamientos de los sujetos que podrían desbaratar el objetivo científico implicado en el diseño, pese a que con el recurso a tal estrategia se podría estar vulnerando el debido Consentimiento Informado con que los participantes deben acceder a enrolarse en el correspondiente plan de investigación.

Una cuestión ética también altamente diferencial y en extremo delicada, más propia de cierto tipo de investigaciones sociales -probablemente recurrentes en aquellas del campo de la psicología o de la educación-, sea la eventual posibilidad de generar una revictimización de los participantes como producto no programado de la propia intervención. Esta, sin duda, es una circunstancia que debe mover al investigador social que enfrente este tipo de riesgos a lograr un diseño metodológico que pueda extremar la previsión de sus ocurrencias, anticipándolos razonablemente y adoptando con todo rigor las precauciones suficientes y necesarias para su contención y administración efectiva.

Por otra parte, y principalmente en estudios científico-sociales desarrollados en las disciplinas de la sociología o la antropología, citando un par de ejemplos, se impone la necesidad ética de otorgar reconocimiento a la exigencia de atención primordial por las peculiaridades culturales e identitarias propias de la población en estudio (los lineamientos establecidos en el Convenio 169 de la OIT son referenciales en este sentido). Esto porque la investigación no debe ser entendida solo como un procedimiento técnico; debe identificar claramente los valores y derechos humanos involucrados en su formulación. Debe resguardar integralmente a los individuos y fundarse en el respeto por su dignidad y la del conjunto de la sociedad, como así 
mismo, tender a una promoción del desarrollo humano de las comunidades. Ello dice relación, a su vez, con el imperativo de reconocer y respetar las normativas, las lógicas y los patrones específicos de funcionamiento o comportamiento colectivo cada vez que se busca intervenir con propósitos científicos sobre espacios sociales e institucionales construidos. De igual manera, debe cumplirse con el manejo reservado y confidencial del patrimonio material e inmaterial de la población estudiada, así como de la documentación personal o registros biográficos aportados por los sujetos de la intervención para complemento de los datos levantados por la investigación. Otro tanto es necesario hacer para mantener los resguardos y precauciones específicas para la conservación y debida puesta en valor del patrimonio material cultural y de los monumentos nacionales (lugares, ruinas, construcciones u objetos de carácter histórico o artístico; los enterratorios o cementerios u otros restos de los aborígenes, las piezas u objetos antropoarqueológicos, paleontológicos o de formación natural, que existan bajo o sobre la superficie del territorio nacional o en la plataforma submarina de sus aguas jurisdiccionales) estudiados por la investigación, sujetos a regulación por la normativa existente (en Chile esto está representado en la Ley 17.288). Un asunto muy particular en este sentido dice relación con la necesidad de cumplir con el compromiso de declaración ante la autoridad competente local de aquellos hallazgos imprevistos de restos biológicos humanos no considerados como parte del protocolo de la investigación validado por el organismo responsable.

Estos factores de distintividad de la investigación social podrían permitirle también al investigador social reflexionar, ponderadamente, por cierto, en la eventual flexibilidad que debería tener en cuenta en la formulación del instrumento de Consentimiento o Asentimiento Informado mediante el cual los sujetos de la intervención se involucran y participan en ella en calidad de proveedores de información. En este caso específico, el requisito legalmente establecido de proveer aquella información que favorece la participación debería establecerse según las características peculiares de la población en estudio y en gran medida dependerá de los procedimientos de contacto que el investigador pueda establecer con los sujetos de la intervención. Ello es particularmente importante de considerar en virtud del carácter excepcional de ciertas poblaciones que se busca conocer y que podrían eventualmente no contar con las condiciones, facultades o competencias con las que el acto de consentimiento se ha entendido legalmente que debe suscribirse bajo otras condiciones de normalidad. Este sería el caso, por 
ejemplo, de estudios en los cuales se quiere levantar información a partir de población inmigrante en condición de ilegalidad, población preescolar, adultos mayores, sujetos analfabetos, discapacitados físicos, o población así llamada cautiva, pueblos originarios, u otros semejantes, ante los cuales el cumplimiento exhaustivo del requisito de obtención de su participación, previo acto de suscripción de un Consentimiento Informado, resulta imposible materialmente o presenta una traba insalvable para la continuidad del plan investigativo.

De todos modos y, en cualquier caso, el investigador social siempre deberá esforzarse por conceder a los participantes la posibilidad de que puedan hacer expresión voluntaria y explícita de aceptación o rechazo y seleccionar conforme a su propia decisión individual todos o solo algunos de los diversos formatos de registro de la información (encuestas, entrevistas, grabaciones, etc.) que los va a involucrar y que busca ser levantada por la intervención. Estas consideraciones, y muchas otras semejantes que sería demasiado largo enumerar aquí, hacen que la consolidación de una perspectiva ética de regulación para la investigación social adquiera un carácter cada vez más imprescindible. Ello se hace aún más acuciante en los países menos poderosos del mundo, donde residen los más altos porcentajes de las poblaciones vulnerables que habitan el planeta, justamente las que han padecido las mayores catástrofes globales de las últimas décadas, como el VIH/sida, las migraciones forzadas o las guerras civiles. Esto, porque se trata de poblaciones vulnerables, que se encuentran a menudo en situación de desmedro para otorgar consentimiento y ejercer libremente su derecho a elegir y participar en la investigación. Estas vulnerabilidades justifican, y hacen aún más exigible su resguardo y la supervisión ética más estricta posible. Sin embargo, paradójicamente, son las regiones del mundo que presentan desafíos a veces demasiado difíciles para la organización y ejecución de la supervisión ética (Webster et al., 2004). Fundamentalmente, esta paradoja obedece a que los modelos occidentales más clásicos de la ética tienden a descansar en principios tales como la "primacía del individuo". $\mathrm{El}$ individuo en Occidente es a la vez el depositario de los derechos y el portador de deberes recíprocos de los derechos de otros.

Pero, este énfasis puede ser curioso fuera del ámbito de la ética occidental, donde el individuo puede tener menor prioridad y estar sujeto a conceptos más amplios de parentesco o de la comunidad. En muchos países, los conceptos de respeto a la familia y la comunidad son tanto o más importantes que los conceptos de autonomía y "derechos individuales". Lo determinante es que el debate y la discusión en torno a este tema requiere que se discuta contextualizadamente 
al respecto, en términos de la cultura y de los sistemas de pensamiento locales inherentes específicamente a los países en vías de desarrollo.

\section{Promover el componente ético de la investigación social}

Ahora bien, en general, podría decirse con poco margen de error que en la investigación social prevalece una falta de conciencia respecto a la ética y el respeto por las personas, que afecta tanto a los investigadores como a los sujetos estudiados, posiblemente debido a una carencia en la formación en ética de investigación de estos profesionales, la que debe ser necesariamente subsanada en el futuro más próximo. El establecimiento de regulaciones éticas puede contribuir a producir cambios en la mentalidad de los investigadores sociales. Algunos efectos positivos podrían ser la instauración de mecanismos para la discusión abierta de los problemas éticos que genera la investigación social y la práctica de la revisión ética de los diseños de investigación.

La forma de investigar procesos sociales no debe excluir el componente ético, sino todo lo contrario, debe promoverlo, enfatizarlo. Desde el punto de vista de los procedimientos, estos deben manifestar un espíritu democrático y fomentar opciones significativas de participación de la población investigada. Tal participación debe asegurarse a partir del establecimiento de lazos comunicativos directos con los participantes, de manera que puedan expresarse con libertad. Por su parte, el carácter democrático debe cautelarse y propiciarse a partir del intento de instaurar metodologías de tipo horizontal donde la información fluya con transparencia. También deben agotarse los esfuerzos para mantener un clima que favorezca la discusión entre los participantes. En este sentido, a veces puede resultar necesario, en vez de evitar el conflicto, propiciarlo en una expresión de bajo impacto, a fin de que el otro se sienta escuchado y sienta que su punto de vista tiene un valor. Además, el investigador social debe promover el trabajo en equipo, donde el sentido de responsabilidad grupal genere lazos de copertenencia y reconocimiento de los participantes.

Particular cuidado deberá tener el investigador social de no establecer metodologías que apunten en un sentido contrario al anteriormente establecido. Para asegurar el cumplimiento de los resguardos éticos en el procedimiento y planificación metodológica, el investigador debe 
tener a la vista siempre las creencias, valores e ideologías de los sujetos investigados; así también debe tomar conciencia de la forma en que sus propias creencias y marcos de referencias pudieran intervenir de manera prejuiciada en la ejecución del proyecto investigativo. Al respecto, se recomienda que el investigador reconozca la individualidad de los sujetos, como parte constitutiva de su proceso indagador. "Ello implica que las ideologías, las identidades, los juicios y prejuicios y todos los elementos de la cultura impregnen los propósitos, el problema, el objeto de estudio, los métodos y los instrumentos" (Sañudo, 2006, p. 92). De esta manera, se entiende que: "Una mala ciencia no es ética", y esto implica que una investigación que usa una metodología inadecuada en el tratamiento con seres humanos, más aún, cuando se trata de niños, no es ética puesto que no está generando un conocimiento confiable. Es más, una investigación valiosa en sus fines debe ser invalidada si acaso en sus procedimientos pasa a llevar algunos de los principios señalados como insoslayables para el resguardo de las personas.

\section{Uso de la información: Responsabilidades, derechos y riesgos del investigador social}

En la ejecución del proyecto investigativo social se deben cautelar dos principios fundamentales: el respeto a la privacidad y la responsabilidad frente a la confidencialidad de la información. La forma de asegurar el cumplimiento de estos principios debe quedar explicitada en el Consentimiento Informado que los participantes de la investigación social tienen que suscribir libre, consciente y voluntariamente. Este consentimiento debe tener una doble matriz, donde, a la vez que asegure el derecho del participante de elegir qué ideas, valores o creencias desea compartir con el investigador, también cautele su derecho de no entregar ninguna información que no desee compartir.

Es imprescindible asegurar que la cautela de ambos principios no sea solo un ejercicio formal, destinado a proteger al investigador frente a una posible querella de los afectados, sino un acto de profunda conciencia ética, enraizado en la propia moral del investigador y plasmado en una metodología donde pueda visualizarse con claridad la forma en que el reconocimiento de los principios será asegurado por la investigación en curso. Se hace necesario, así, disponer un 
procedimiento eficaz para evaluar la confidencialidad de la información que se va obteniendo, tanto como para visualizar ajustadamente a la realidad los niveles de riesgo que esta presenta para los sujetos que la suministran. Sobre esta base, se deben elaborar los protocolos correspondientes al manejo de la información, los cuales deben clarificar, entre otras cosas, la forma de acceder a ella, el uso que se le dará, la persona que estará encargada de su resguardo y almacenamiento, el lugar donde ello se realizará y la metodología de eliminación o destrucción posterior de los datos una vez que hayan sido utilizados, según proceda y pueda establecerlo la normativa vigente.

Si pensamos en el trabajo con menores, el acceso a la información puede volverse un tema delicado, por lo que es necesario aumentar estos mismos resguardos. El lugar de las entrevistas, por citar un solo ejemplo, debe ser seguro y confiable. Una sala u oficina solo será confiable si se puede asegurar la privacidad, esto es, que los participantes no serán vistos, escuchados o interrumpidos. Si la entrevista acontece en el hogar, es necesario cautelar que la presencia y la opinión de los menores no esté interferida por la presencia influyente de los padres o hermanos. Muy importante, además, es que el investigador exija el cumplimiento de estos compromisos a sus colaboradores y a todo el personal de apoyo asociado a la investigación sean estos entrevistadores, traductores o conductores-, de manera que todos ellos preserven de igual manera la misma confidencialidad.

Evidentemente, durante el último tiempo y debido a las modificaciones tecnológicas que ha experimentado la sociedad contemporánea, el resguardo de la privacidad y la confidencialidad de la información levantada por la investigación científica se vuelve más difícil de asegurar. La necesidad de recurrir a soportes informáticos para su almacenamiento la lleva a incurrir en riesgos de filtración de los datos que podrían tornarse inmanejables para la ciencia.

En este sentido, el almacenamiento seguro de la información puede eventualmente llegar a no depender tan solo de la voluntad de resguardo que para ella disponga el investigador. Por lo mismo, el trabajo de Graham et al., Investigación Ética con Niños (Ethical Research Involving Children) (ERIC desde ahora en adelante, por su sigla en inglés) (2013), propone que "la confidencialidad puede asegurarse mediante el uso de protocolos cifrados. Tales protocolos implican el proceso de alterar los datos a fin de que resulten incomprensibles para cualquier intruso" (2013, p. 76). 


\section{Conclusiones}

El investigador tiene la responsabilidad de conducir su investigación sobre un soporte ético, lo cual, al decir de Sañudo, puede expresarse en cinco ejes: a) responsabilizarse con el conocimiento mismo; b) hacer que su investigación sea un real aporte al saber, de tal forma que sus conclusiones puedan ser entendidas y divulgadas como un patrimonio de la humanidad; c) conectar su investigación con un principio de utilidad y rendimiento para que la sociedad pueda usufructuar de los beneficios de la investigación; d) responsabilizarse de cautelar la seguridad y la integridad de todos los miembros que participan en la investigación, declarando cualquier conflicto de interés que pudiera interferir sobre el necesario criterio de neutralidad que la ciencia exige, y por último, e) admitir la responsabilidad de reconocer cuando sus competencias no son suficientes para llevar a cabo su investigación (Sañudo, 2006).

Por otra parte, el investigador social es sujeto de derechos por sobre los resultados de su investigación, distinguiéndose tres tipos de derechos fundamentales que deben serle reconocidos. En primer lugar, su derecho de autor y su derecho a recibir los beneficios materiales que esto pueda suponer. En segundo lugar, el derecho a que tanto él como su investigación no sean discriminados por razones de raza, género, condición social o cualquier otro precepto que se oponga al principio de equidad. En tercer lugar, su derecho al reconocimiento, en tanto que su trabajo es fruto de su esfuerzo y creatividad y una expresión de lo que es y puede hacer.

Asimismo, el investigador social también está sujeto a diversos tipos de riesgos, muchos de los cuales también pueden ser considerados desde el punto de vista ético. No solamente porque pueda provocar daños a la población investigada, sino porque él mismo debe verse impulsado a adoptar resguardos respecto de los peligros a los que su propia investigación pueda exponerlo. Los peligros directos que el investigador podría enfrentar se refieren a tres ámbitos: aquellos referidos al financiamiento de la investigación, aquellos relacionados con la institución o comunidad intervenida y los que provienen de los sujetos y su entorno.

Las posibilidades de riesgo van desde la intención de redireccionar la investigación hasta cooptarla directamente. En relación con esto, habría que decir que clarificar los orígenes del financiamiento le ayuda al investigador a establecer las responsabilidades que asume con respecto al mismo. Si los fondos son de origen público, el Estado, a partir de sus organizaciones 
intermedias, podría tratar de alinear la heurística investigativa hacia los diagnósticos y tratamientos ya establecidos en las políticas gubernamentales. Si los financiamientos son privados, siempre puede existir la tentación de establecer presión para que la investigación afirme ciertos compromisos corporativos establecidos previamente a la investigación. Las instituciones sociales están conformadas por estructuras complejas y jerárquicas en las que el poder se desplaza activa y productivamente. En ese contexto, las posibilidades de que una investigación entre en contradicción con un flujo de poder son altísimas. Bastaría con que la investigación develara una violación al principio de autonomía de los sujetos o un ejercicio coercitivo de las prácticas sociales para que tal enunciación pueda ser objeto de cuestionamiento por parte de las autoridades o para que los organismos involucrados colocaran trabas al quehacer del investigador, restringieran el acceso a la información o simplemente se opusieran frontalmente a ella. El investigador deberá entonces tener cuidado con lo que significa el riesgo institucional para su ejercicio profesional.

Por último, aunque no menos significativo, se podría señalar que están los peligros directos que se ciernen sobre el investigador social y que provienen de una población investigada que se siente amenazada o que no logra distinguir los beneficios de la investigación. Tales agresiones pueden manifestarse como violencia verbal o física ejercida sobre el investigador o sus colaboradores. En algunos casos, esa violencia puede provenir del entorno familiar o social de los sujetos investigados; pensemos lo que significa una investigación en condiciones de vulnerabilidad o en adolescentes con problemas conductuales severos.

De esta forma, se hace necesario establecer planes de contingencia que aseguren la integridad del investigador, tales como sistemas de comunicación eficientes, transporte seguro, redes asistenciales preestablecidas y por sobre todo protocolos ad hoc que puedan medir con claridad los niveles de riesgo y las respuestas oportunas a los mismos. Sumado a los riesgos de la violencia física, es necesario abordar los riesgos psicológicos que puede traer la investigación para el investigador social. Si el estudio se centra sobre situaciones dramáticas o de daño permanente para los sujetos, esto pone inmediatamente al investigador en condición de riesgo, los niveles de angustia y estrés aumentan proporcionalmente a la gravedad de la situación, por tanto, una revisión permanente de los estándares de presión que recaen sobre el investigador, así como los diagnósticos oportunos de posibles debilidades personales ayudan a disminuir -aun cuando nunca suprimir- tales riesgos. 
El investigador debe tener conciencia del impacto que tiene su investigación sobre el nicho ecológico en que se desenvuelve. En un mundo donde los recursos son cada vez más escasos, la responsabilidad del investigador de agregar un valor social a su investigación es un requerimiento decididamente ético. Sumado a lo anterior está la responsabilidad con las generaciones futuras, que fue señalada por Vasak (1977) en el precepto de solidaridad. Según este precepto, la responsabilidad se desplaza hacia el conjunto de la humanidad por vía de la cautela de valores como la paz, la calidad de vida o el respeto para con el medio ambiente. Y en este último sentido, es de total pertinencia que opere un principio de responsabilidad hacia la naturaleza. Recordemos en este mismo sentido que muchos estudios tienen que ver con comunidades locales, ubicadas en regiones donde el contacto con la naturaleza no solo es una relación ancestral de tipo simbólico, sino que también una fuente de sustento material permanente y de sobrevivencia para sus habitantes. De tal forma, el respeto por la comunidad se traslada a la figura de un respeto por la naturaleza. Preservar la naturaleza es preservar al ser humano. El uno (el sujeto de la ética occidental) no existe sin el otro y, por tanto, cabría hablar, tal como lo hace Hans Jonas, de una interpelación moral, "ya no es un sinsentido preguntar si el estado de la naturaleza extrahumana $[. .$.$] se ha convertido precisamente por ello en un bien$ encomendado a nuestra tutela y puede plantearnos algo así como una exigencia moral, no solo en razón de nosotros, sino también en razón de ella y por su derecho propio" (Jonas, 1995, p. 35). Toda investigación social que desee validarse desde una perspectiva ética debe entonces considerar también la forma en que se expresa la responsabilidad hacia la comunidad y el nicho ecológico en que esta se inserta.

De esta manera, podemos admitir que toda investigación social tiene de por sí un componente social que reviste una doble significación. Por una parte, la tiene en la medida en que el conocimiento mismo extraído es un bien que debe ser puesto al servicio de la sociedad; mientras que, por otra, la tiene en la medida en que el conocimiento se inserta en términos procedimentales al interior de una comunidad que no es un actor pasivo frente a la investigación.

En conformidad con la responsabilidad ética que debe orientar la labor del investigador social, este debe tener conciencia en todo momento del principio de beneficencia que mueve su quehacer, de tal forma que, enfrentado al proceso que pone en marcha su investigación, debe preguntarse acerca de la mejor forma en que esta podría beneficiar a la comunidad en que se inserta. 


\section{Referencias bibliográficas}

$\varphi$ Jonas, H. (1995) Elprincipio de responsabilidad. Ensayo de una ética para la civilización tecnológica. Barcelona: Herder.

$\varphi$ MacIntyre, A. (2006). Historia de la Ética. Barcelona: Paidós.

$\varphi$ Merton, R. K. (1977). La sociología de la ciencia. Madrid: Alianza.

$\varphi$ Rose, N (2007). Políticas de la vida. Biomedicina, poder y subjetividad en el silog XXI. Buenos Aires: UNIPE Editorial Universitaria.

$\varphi$ Sañudo, L. (2006). "La ética en la investigación educativa". Revista Hallargos, 6: 83-98. Bogotá: Universidad Santo Tomás.

$\varphi$ Vasak, K. (1977). Human Rights: A Thirty Year Struggle: The Sustained Efforts to give Force of law to the Universal Declaration of Human Rights. UNESCO, Paris.Courier, 30 (11): $28-29$ y 32.

$\varphi$ Webster, A. et al. (2014). "Crossing boundaries: social science, health and bioscience research and the process of ethics review". En ESRC Research Ethis Framewoek. Oxford: University of York and Oxford Brookes University.

$\varphi$ Wittgensetin, L. (1997) Tractatus Logico-Philosophicus. Barcelona. Altaya. 
